\title{
Outcomes of Craniofacial Open Surgery in Octogenarians
}

\author{
Barak Ringel ${ }^{1}$ Narin N. Carmel-Neiderman ${ }^{1}$ Daniel Ben-Ner ${ }^{1} \quad$ Aviyah Pery $^{1}$ Ahmad Safadi ${ }^{1}$ \\ Avraham Abergel $^{1}$ Nevo Margalit ${ }^{2}$ Dan M. Fliss ${ }^{1}$
}

${ }^{1}$ Departments of Otolaryngology Head and Neck Surgery and Maxillofacial Surgery, Tel Aviv Sourasky Medical Center, Tel Aviv, Israel, Sackler School of Medicine, Tel Aviv University, Tel Aviv, Israel

2 Departments of Neurosurgery, Tel Aviv Sourasky Medical Center, Tel Aviv, Israel, Sackler School of Medicine, Tel Aviv University, Tel Aviv, Israel

Address for correspondence Dan M. Fliss, MD, Department of Otolaryngology Head and Neck Surgery and Maxillofacial Surgery, Tel Aviv Sourasky Medical Center, Weizman Street 6, Tel Aviv 6423906, Israel (e-mail: danf@tlvmc.gov.il).

J Neurol Surg B 2018;79:515-521.

\begin{abstract}
Keywords

- skull base surgery

- octogenarians

- complications

- elderly

Introduction The steady increase in average life expectancy has led to a rise in the number of referrals of elderly patients for major operations. It is not clear whether age itself is a risk factor for morbidity and mortality after skull base operations. We investigated a possible link among a cohort of patients older than 80 years of age who underwent those surgeries in our department.

Methods We conducted a retrospective analysis of all patients who underwent skull base surgery at the TASMC (Tel Aviv Sourasky Medical Center) between 2000 and 2016. Results A total of 369 patients underwent open skull base surgeries in our institution, and 13 were patients older than 80 years. The median age of the octogenarians was 83.4 (range 80-89), and the male-to-female ratio was 7:6. Twelve patients had major systemic comorbidities. Four patients had major complications associated with surgery: three had early wound complications, and one each had early central nervous system complications, early and late systemic complications, and late orbital complications. This complication rate is comparable to that of our younger group of 356 patients. The overall survival rate was measured for 30 days, 1 year, and 3 years, and it was not significantly different between the octogenarians and that of the younger patients. Further comparison of the elderly group with 13 matched younger patients revealed no difference of morbidity and mortality between the two groups.

Conclusions Despite their systemic comorbidities, the morbidity and mortality rates associated with skull base surgery in octogenarians appear to be comparable to that of younger patients undergoing the same procedures.
\end{abstract}

\section{Introduction}

In Israel, the average life expectancy is currently 84 years for females and 82 years for males (http://data.worldbank.org/ country/israel). The increasing worldwide life expectancy has led to a trend to define "old" by physical and mental characteristics rather than by chronologic age. The cutoff age for defining old has changed in the recent years from 65 to 75 and even 80 years. Head and neck cancer morbidity and mortality are age related, and the prevalence of head and neck cancer octogenarians in 2016 was $\sim 67$ cases per 1,00,000 persons (http://www.aihw.gov.au/cancer/headand-neck/\#source 1$){ }^{1-4}$

With the advancement of medical knowledge and technology, performing major medical procedures in advanced-aged patients has gradually become more conceivable and received

October 7, 2017

accepted after revision

January 13, 2018

published online

March 9, 2018 (c) 2018 Georg Thieme Verlag KG Stuttgart · New York
DOI https://doi.org/

10.1055/s-0038-1635077. ISSN 2193-6331. 
feasible. ${ }^{5-8}$ Studies that focused on septuagenarians who underwent head and neck surgeries, however, reported that they had a lower quality of life, an increased incidence of complications and lower survival rates than younger patients. ${ }^{9,10}$

The objectives of this study are to investigate whether being aged 80 and 89 years is an independent risk factor for morbidity and mortality after open skull base resection and reconstruction, and to compare postoperative morbidity and short-term mortality between the octogenarian study group and a cohort of younger matched patients.

\section{Patients and Methods}

We reviewed the medical records of all patients who were operated for skull base lesions at the Tel Aviv Sourasky Medical Center between 2000 and 2016. This study was approved by the Institutional Review Board (IRB 0730-TLV-14), and patient consent was waived. A computer-assisted search performed by the institutional operation registry identified 446 patients who were operated for skull base lesions.

A total of 369 patients underwent open skull base surgery, of whom 13 were older than 80 years. The medical charts of all the patients were reviewed to retrieve the following data: demographics, imaging studies, comorbidities, tumor histology, disease characteristics, surgical approach and extension, reconstruction method, surgical pathology, and postoperative morbidity and mortality. Follow-up data were obtained from the clinical notes, imaging studies, and histopathological results for all patients.

Complications were referred to as early ( $<30$ days postsurgery) and late ( $>30$ days postsurgery), and they were divided into wound (local infection, fistula, osteonecrosis, seroma, dehiscence), central nervous system (cerebrospinal fluid leak, meningitis, hemorrhage, neuronal injury, pneumocephalus, cerebral edema, seizures), systemic (sepsis, cardiovascular, pulmonary), and orbital (optic nerve or retinal injury, globe injury, rectus muscle injury, hematoma, ectropion, telecanthus, ptosis, epiphora, enophthalmos, diplopia, decreased visual acuity, orbital cellulitis).

We first compared the data of 13 octogenarian patients (defined as "group A") to those of all 356 patients younger than 80 years of age (defined as "group B") and then to 13 matched younger ones (defined as "group C"). Patient matching was based on the following defined variables: gender, major and minor comorbidities, preoperative treatment (surgery/chemoradiotherapy), status of the disease (primary/recurrence/persistence), surgical intracranial and dural extension, benign or malignant pathology, and site of skull base involvement (lateral/anterior).

In addition to 30-day and 3-year survival, we measured the 1-year survival due to natural mortality and life expectancy at $\geq 80$ years for calculating overall survival of the octogenarians.

\section{Statistical Analyses}

Categorical variables were described using frequency and percentage. Continuous variables were evaluated for normal distribution using histograms and $\mathrm{Q}-\mathrm{Q}$ plots. Continuous variables were expressed as median and interquartile range. Categorical variables were compared between categories using chi-square test or Fisher's exact test. The MannWhitney test was used to compare continuous variables between age categories. Survival over the follow-up time was described using a Kaplan-Meier curve. The log-rank test was used to compare between age groups. The propensity score was calculated as the probability of age $>80$ years using logistic regression, which included gender, major and minor comorbidities, preoperative treatment (surgery/chemoradiotherapy), status of the disease (primary/recurrence/ persistence), surgical intracranial and dural extension, benign or malignant pathology, and site of the skull base involvement (lateral/anterior). A difference up to $5 \%$ was considered acceptable for matching. After matching, the groups were compared using McNemar test for categorical variables and the Wilcoxon signed test for continuous variables. A stratified Cox regression was used to compare survival between groups. All statistical tests were two-tailed, and a $p$ value $<0.05$ was considered statistically significant. All statistical analyses were performed using SPSS (IBM Corp. Released 2014. IBM SPSS Statistics for Windows, Version 22.0., IBM Corp., Armonk, New York, United States).

\section{Results}

The patient characteristics for each group are listed in - Table 1 . Group A comprised six women and seven men who ranged in age from 80 years to 89 years (median 83.4). Group A had a significantly higher rate of major comorbidities, such as ischemic heart disease, cardiac failure, high blood pressure, asthma or chronic obstructive airway disease, diabetes, and renal or liver impairment when compared with group $B$ (92\% vs $41.9 \%, p<0.01)$. Group A also had a significantly higher malignancy rate compared with group B (76.9\% vs $37.4 \%$, $p<0.004$ ). Patients in group A presented with more recurrent/persistent malignancy. Significantly more patients from group A were treated with neoadjuvant radiochemotherapy or prior surgery and with adjuvant radiochemotherapy than patients in group B. They also had more lateral than anterior skull base operations. - Table $\mathbf{2}$ describes each individual patient's characteristics, pathology, performed operation and status on last follow up.

- Table 3 compares the surgical extension to skull base compartments and free flap reconstruction in the three groups. - Table 4 shows no significant difference between group A and B in terms of wound, central nervous system, and systemic or orbital complications. Moreover, most of the short- and long-term postoperative complications were less frequent among group A compared with group $\mathrm{B}$, while the 30-day mortality rate was similar for both groups ( $0 \%$ vs $1.1 \%$, $p>0.999$ ) as was the 1 -year survival rate (-Fig. 1). As shown in - Tables 4 and 5 and -Figs. 1 and 2, there were no significant differences in the complications rates between group $\mathrm{A}$ and $\mathrm{C}$ and the comparable postoperative mortality rates at 30 days, 1 year, and 3 years were better for group $A$ compared with group $\mathrm{C}$. 
Table 1 Patients and tumor characteristics

\begin{tabular}{|l|l|l|l|l|l|}
\hline Characteristic & $\begin{array}{l}\text { Age }>80 \text { years } \\
\text { (group A) } \\
\text { 13 Pts. (\%) }\end{array}$ & $\begin{array}{l}\text { Age }<80 \text { years } \\
\text { (group B) } \\
\mathbf{3 5 6} \text { Pts. (\%) }\end{array}$ & $\begin{array}{l}\text { Age }<80 \text { years } \\
\text { (group A vs B) } \\
\text { p-Value }\end{array}$ & $\begin{array}{l}\text { Matched } \\
\text { (group C) age } \\
<80 \text { years } \\
13 \text { Pts (\%) }\end{array}$ & $\begin{array}{l}\text { Matched age } \\
<80 \text { years } \\
\text { (group A vs C) } \\
p \text {-Value }\end{array}$ \\
\hline Age (years, (IQR)) & $83.4(80.6,84.5)$ & $51.8(42,76.3)$ & $<0.01$ & $66.5(60.5,72.9)$ & $<0.01$ \\
\hline Male & $7(53.8)$ & $202(55)$ & 0.932 & $7(53.8)$ & $>0.999$ \\
\hline Major comorbidities & $12(92.3)$ & $147(41.9)$ & $<0.01$ & $11(84.6)$ & $>0.999$ \\
\hline Minor comorbidities & $0(0)$ & $39(11.1)$ & 0.376 & $1(7.7)$ & 0.317 \\
\hline $\begin{array}{l}\text { Recurrent/persistent } \\
\text { disease }\end{array}$ & $9(69.2)$ & $171(49.6)$ & 0.164 & $7(53.8)$ & 0.625 \\
\hline Malignant pathology & $10(76.9)$ & $134(37.4)$ & 0.004 & $12(92.3)$ & 0.5 \\
\hline Anterior skull base & $3(23.1)$ & $236(66.3)$ & 0.031 & $1(7.7)$ & 0.625 \\
\hline Lateral skull base & $10(76.9)$ & $120(33.7)$ & 0.031 & $12(92.3)$ & 0.625 \\
\hline Lumbar drainage & $1(8.3)$ & $138(43)$ & 0.017 & $8(61.5)$ & $>0.999$ \\
\hline Preoperative surgery & $7(53.8)$ & $159(45.2)$ & 0.537 & $5(38.5)$ & $>0.999$ \\
\hline $\begin{array}{l}\text { Preoperative } \\
\text { chemoradiotherapy }\end{array}$ & $5(38.5)$ & $63(17.9)$ & 0.074 & $3(23.1)$ & $>0.999$ \\
\hline $\begin{array}{l}\text { Adjuvant } \\
\text { chemoradiotherapy }\end{array}$ & $8(61.5)$ & $88(28)$ & 0.024 & $1(7.7)$ & $>0.999$ \\
\hline Hospitalization days (IQR) & $10(7.5,15)$ & $10(7,13)$ & 0.554 & $1(10)$ & $>0.999$ \\
\hline
\end{tabular}

Abbreviations: IQR, interquartile range; Pts, patients; Yrs, years.

${ }^{a}$ Group C-Thirteen patients matched by gender, major and minor comorbidities, preoperative treatment (surgery/chemoradiotherapy), status of the disease (primary vs recurrence/persistence), surgical intracranial or dural extension, benign or malignant pathology, and site of skull base involvement (lateral/anterior).

\section{Discussion}

Octogenarians are generally considered high-risk candidates for major surgeries. $4,7,8,11$ Open skull base surgeries are prolonged, with a significant insult to an area that may have been previously treated with chemoradiotherapy or prior surgery and might require reconstruction with free flap/local tissue transfer, all of which are factors that may lead to higher postoperative morbidity and mortality rates. There are limited reports in the literature on outcomes after skull base for the octogenarian patient population, and the current study was conducted to address these issues.

Our findings show that patients in group A did not have a higher rate of short-and long-term postoperative complications when compared with patients in group B. These findings were consistent when compared with a larger general cohort (group B) as well as to younger patients with otherwise similar demographic and clinical characteristics (group C).

Group A had a significantly higher rate of major comorbidities and more lesions involving the lateral rather than the anterior skull base regions compared with patients in group $B$. They also had higher rates of malignant disease and were treated more often with neoadjuvant chemoradiotherapy or prior surgery and adjuvant chemoradiotherapy. However, group B had higher rates of intracranial and dural surgical extension compared with group A, while the proportions of primary versus recurrent or persistent disease were similar in both groups (group A and B).

The treatment strategy is chosen by a multidisciplinary team, and some authors state that neoadjuvant chemoradiotherapy might be the best primary treatment depending on patient's and tumor characteristics. ${ }^{12-14}$ Chemoradiotherapy, however, is related to high toxicity, major tissue insult, and other major complications in and of itself. ${ }^{15}$ In spite of the higher rate of major comorbidities and the history of chemoradiotherapy, there was no significant difference in the postoperative complication rates between group A and group B in the current study.

This is in contrast to previous reports on larger elderly patient populations that showed an increased rate of postoperative complications. ${ }^{16,17}$ One international collaborative study group found medical comorbidities, prior radiotherapy, and intracranial invasion as independent predictors for postoperative complications for patients older than 70 years who had undergone skull base surgery. ${ }^{5}$ Another study found that only comorbidities comprised as independent predictor for complications. ${ }^{9}$ A correlation between comorbidities and complications among elderly head and neck surgery patients has also been reported. ${ }^{18}$

To support our findings, we compared group A to a group of 13 younger patients (group C) that was matched by gender, major and minor comorbidities, preoperative 


\begin{tabular}{|c|c|c|c|c|c|c|c|c|c|c|c|c|c|}
\hline 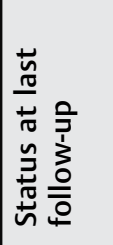 & 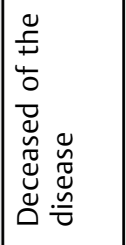 & 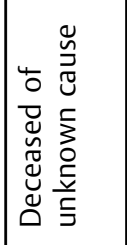 & 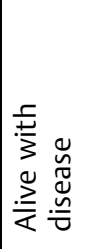 & 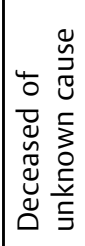 & 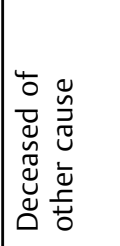 & 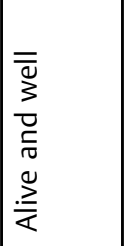 & 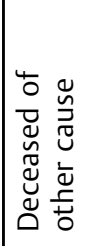 & 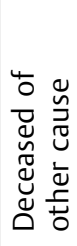 & 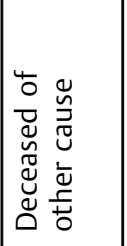 & 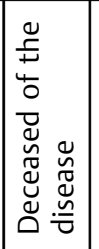 & 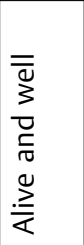 & 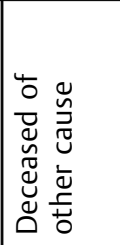 & 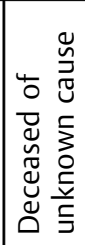 \\
\hline 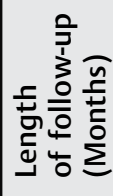 & mà & 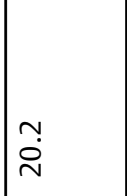 & $\mid \infty$ & $\begin{array}{l}\stackrel{\rho}{r} \\
\dot{\gamma}\end{array}$ & $\hat{m}$ & $\begin{array}{l}\dot{\sim} \\
\dot{\sim}\end{array}$ & $\dot{\sim}$ & $\frac{m}{n}$ & $\begin{array}{c}\underset{\dot{\infty}}{\infty} \\
\text {. }\end{array}$ & $\stackrel{\sim}{\stackrel{n}{\sim}}$ & $\begin{array}{l}\text { Ln } \\
\text { in }\end{array}$ & $\begin{array}{l}\text { mà } \\
\stackrel{0}{0}\end{array}$ & ச் \\
\hline 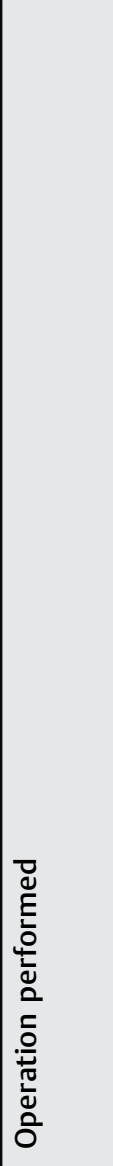 & 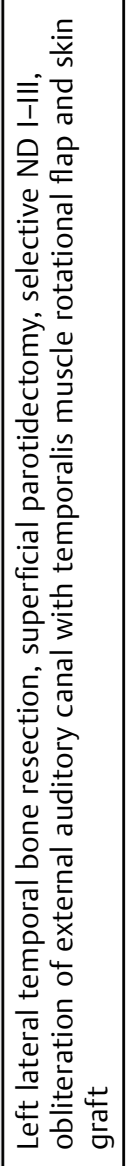 & 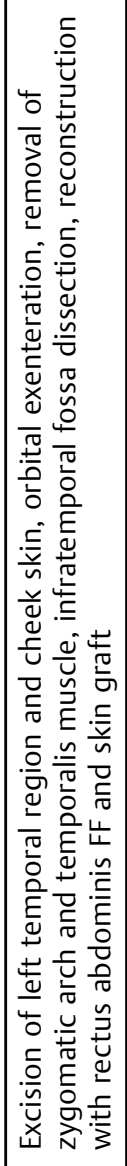 & 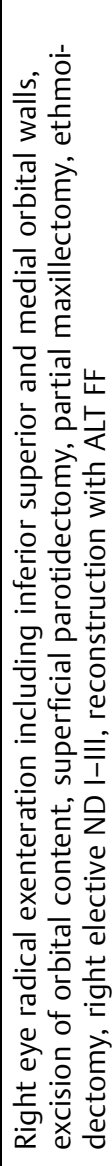 & 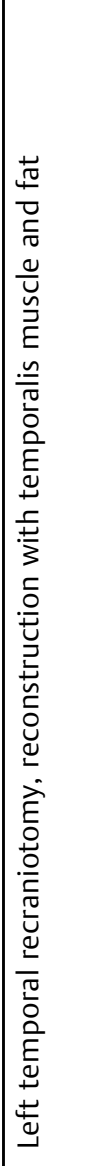 & 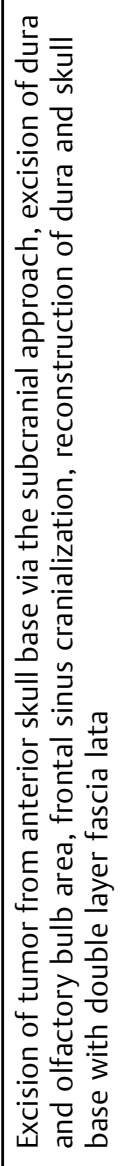 & 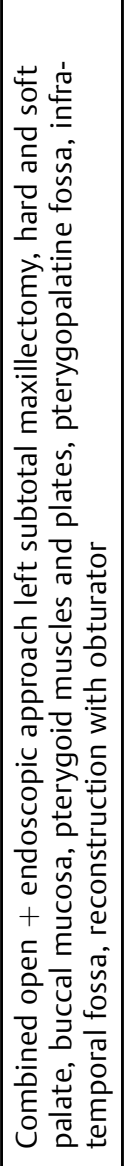 & 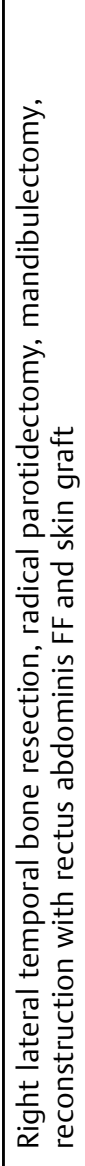 & 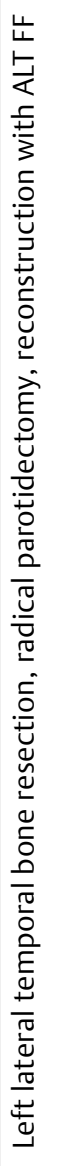 & 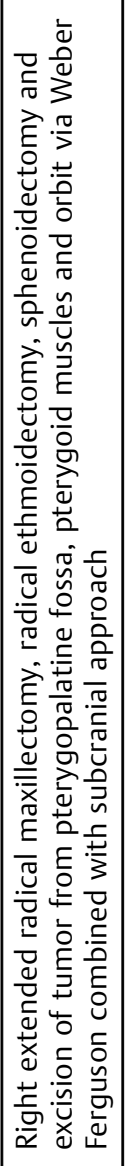 & 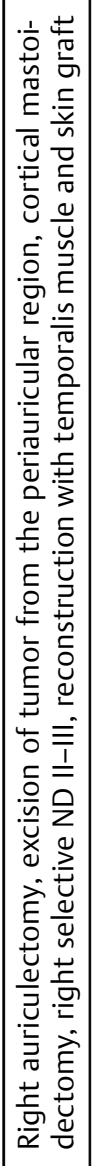 & 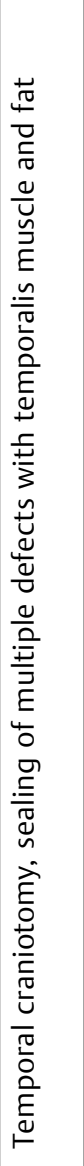 & 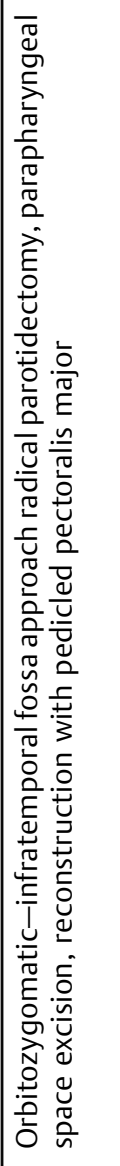 & 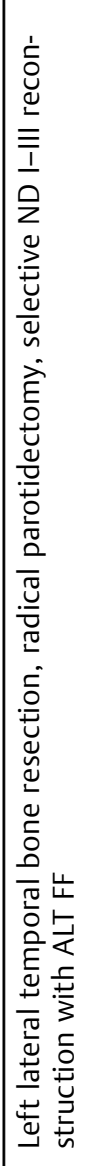 \\
\hline 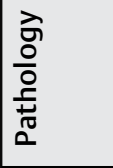 & $\begin{array}{l}\frac{0}{E} \\
\stackrel{0}{0} \\
\frac{\Gamma}{\sigma} \\
\frac{d}{2}\end{array}$ & $\underset{\sim}{\cup}$ & 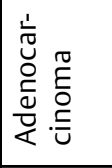 & 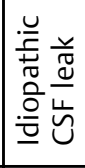 & 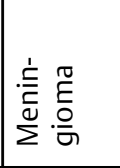 & 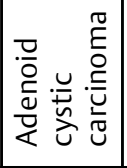 & 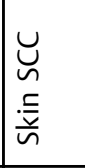 & 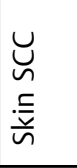 & $\ddot{\sim}$ & $\begin{array}{l}u \\
u \\
. \bar{v} \\
\bar{v}\end{array}$ & 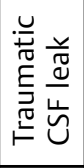 & 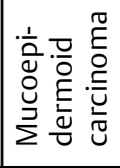 & u \\
\hline 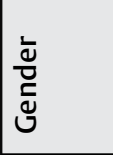 & L & $\Sigma$ & 4 & $\Sigma$ & L & $\Sigma$ & $\Sigma$ & $\Sigma$ & $\Sigma$ & $\Sigma$ & $\leftarrow$ & 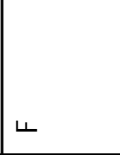 & 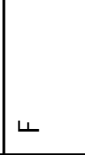 \\
\hline 苂 & $\bar{\infty}$ & $\mid \begin{array}{l}m \\
\infty \\
\infty\end{array}$ & $\begin{array}{l}n \\
\stackrel{0}{\infty} \\
\infty\end{array}$ & $\begin{array}{l}0 \\
\dot{\infty}\end{array}$ & $\frac{m}{\infty}$ & $\frac{\infty}{\dot{\infty}}$ & $\mid \infty$ & 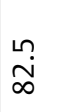 & $\begin{array}{l}\infty \\
\infty \\
\infty\end{array}$ & 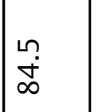 & $\begin{array}{l}0 \\
\infty \\
\infty \\
\infty\end{array}$ & $\begin{array}{l}\hat{1} \\
\infty \\
\infty\end{array}$ & ஜே \\
\hline 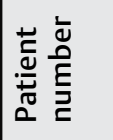 & - & $\sim$ & $m$ & $\nabla$ & เn & 6 & $r$ & $\infty$ & $\sigma$ & $\stackrel{ }{\circ}$ & $\mp$ & $\stackrel{\sim}{\sim}$ & $\stackrel{m}{r}$ \\
\hline
\end{tabular}


Table 3 Surgical extension to skull base compartments and free flap reconstruction

\begin{tabular}{|l|l|l|l|l|l|}
\hline Characteristic & $\begin{array}{l}\text { Age }>80 \text { years } \\
\text { (group A) } \\
\text { 13 Pts. (\%) }\end{array}$ & $\begin{array}{l}\text { Age }<\text { 80 years } \\
\text { (group B) } \\
356 \text { Pts. (\%) }\end{array}$ & $\begin{array}{l}\text { Age }<80 \text { years } \\
\text { (group A vs B) } \\
\text { p-Value }\end{array}$ & $\begin{array}{l}\text { Matched age } \\
<80 \text { years } \\
\text { (group C) } \\
\text { 13 Pts (\%) }\end{array}$ & $\begin{array}{l}\text { Matched }{ }^{\text {age }} \\
<80 \text { years } \\
\text { (group A vs C) } \\
\text {-Value }\end{array}$ \\
\hline Orbital extension & $3(23.1)$ & $141(42.4)$ & 0.165 & $4(30.8)$ & $>0.999$ \\
\hline Intracranial extension & $1(7.7)$ & $175(49.2)$ & 0.003 & $3(23.1)$ & 0.5 \\
\hline $\begin{array}{l}\text { Pterygopalatine fossa } \\
\text { extension }\end{array}$ & $1(7.7)$ & $43(12.1)$ & $>0.999$ & $2(15.4)$ & $>0.999$ \\
\hline Dural extension & $4(30.8)$ & $220(61.8)$ & 0.024 & $4(30.8)$ & $>0.999$ \\
\hline $\begin{array}{l}\text { Infratemporal fossa } \\
\text { extension }\end{array}$ & $5(41.7)$ & $65(20.4)$ & 0.14 & $7(53.8)$ & 0.754 \\
\hline $\begin{array}{l}\text { Cavernous sinus } \\
\text { extension }\end{array}$ & $0(0)$ & $24(7.6)$ & $>0.999$ & $1(7.7)$ & 0.317 \\
\hline $\begin{array}{l}\text { Free flap } \\
\text { reconstruction }\end{array}$ & $3(25)$ & $45(13.9)$ & 0.39 & $4(30.8)$ & $>0.999$ \\
\hline
\end{tabular}

Abbreviations: Pts, patients; Yrs, years.

${ }^{a}$ Group C-Thirteen patients matched by gender, major and minor comorbidities, preoperative treatment (surgery/chemoradiotherapy), status of the disease (primary vs recurrence/persistence), surgical intracranial or dural extension, benign or malignant pathology, and site of skull base involvement (lateral/anterior).

treatment (surgery/chemoradiotherapy), status of the disease (primary vs recurrence/persistence), surgical intracranial or dural extension, benign or malignant pathology, and site of skull base involvement (lateral/anterior). This analysis demonstrated that there was no significant difference in the early and late postoperative complications between these two groups. The mortality rates at 30 days, 1 year, and 3 years were also similar for both groups (group A and C).

Postoperative hospitalization period might correlate to postoperative complications; however, a comparison of the hospitalization period showed no difference between the two groups (group A and C).
Based on the lack of difference in complications and hospitalization time between our three study groups, and the report by Grammatica et al's on the same rate of complications post free flap reconstruction for older and younger patients in head and neck reconstruction, we suggest that the decision of whether to reconstruct the skull base defect with free flaps should probably not be based upon age. 6

There are several limitations to this study that bear mention. It has a relatively small number of octogenarian patients, and its design makes it susceptible to the usual deficiencies in data recording and collection inherent to

Table 4 Complication and short-term mortality rates

\begin{tabular}{|c|c|c|c|c|c|}
\hline Characteristic & $\begin{array}{l}\text { Age }>80 \text { years } \\
\text { (group A) } \\
13 \text { Pts }(\%)\end{array}$ & $\begin{array}{l}\text { Age }<80 \text { years } \\
\text { (group B) } \\
356 \text { Pts (\%) }\end{array}$ & $\begin{array}{l}\text { Age }<80 \text { years } \\
\text { (group } A \text { vs } B \text { ) } \\
p \text {-Value }\end{array}$ & $\begin{array}{l}\text { Matched }{ }^{\mathrm{a}} \text { age } \\
<80 \text { years } \\
\text { (group C) } \\
13 \text { Pts (\%) }\end{array}$ & $\begin{array}{l}\text { Matched }{ }^{\mathrm{a}} \text { age } \\
<80 \text { years } \\
\text { (group A vs C) } \\
\text { p-Value }\end{array}$ \\
\hline Early wound complications & $3(23.1)$ & $29(9.4)$ & $>0.999$ & $3(25)$ & $>0.999$ \\
\hline Late wound complications & $0(0)$ & $41(12.8)$ & 0.397 & $0(0)$ & $>0.999$ \\
\hline Early CNS complications & $1(7.7)$ & $35(11.3)$ & 0.375 & $1(0)$ & $>0.999$ \\
\hline Late CNS complications & $0(0)$ & $24(7.6)$ & $>0.999$ & $0(0)$ & $>0.999$ \\
\hline $\begin{array}{l}\text { Early systemic } \\
\text { complications }\end{array}$ & $1(7.7)$ & 34 (10.9) & 0.623 & $4(30.8)$ & 0.083 \\
\hline $\begin{array}{l}\text { Late systemic } \\
\text { complications }\end{array}$ & $1(7.7)$ & $2(0.7)$ & $>0.999$ & $0(0)$ & $>0.999$ \\
\hline Early orbital complications & $0(0)$ & $7(2.3)$ & $>0.999$ & $0(0)$ & $>0.999$ \\
\hline Late orbital complications & $1(7.7)$ & $23(7.4)$ & 0.546 & $0(0)$ & 0.317 \\
\hline 30-day mortality & $0(0)$ & $4(1.1)$ & $>0.999$ & $3(23.1)$ & 0.046 \\
\hline
\end{tabular}

Abbreviations: CNS, central nervous system; Pts, patients; Yrs, years.

${ }^{a}$ Group C-Thirteen patients matched by gender, major and minor comorbidities, preoperative treatment (surgery/chemoradiotherapy), status of the disease (primary vs recurrence/persistence), surgical intracranial or dural extension, benign or malignant pathology, and site of skull base involvement (lateral/anterior). 


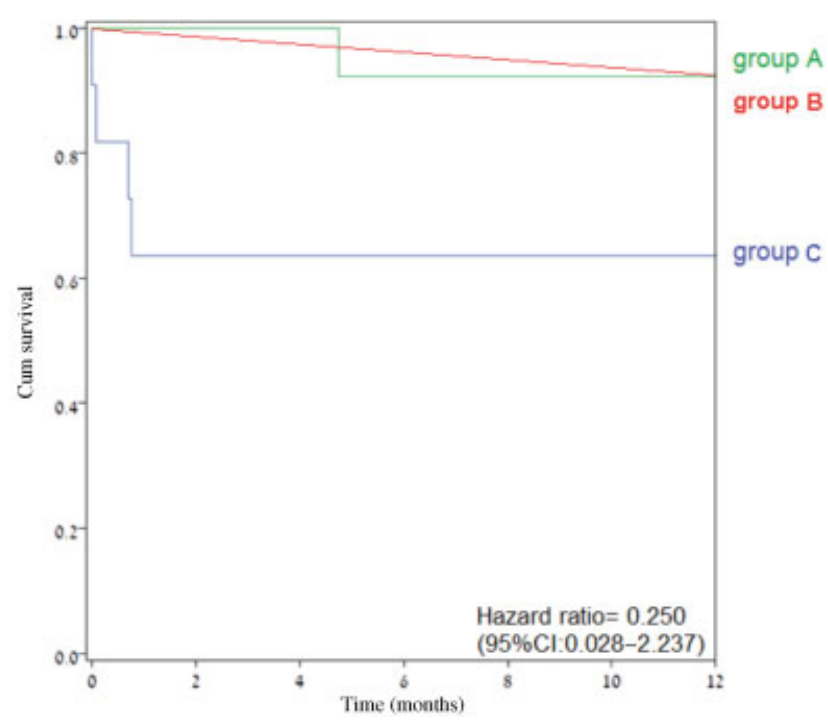

Fig. 1 The 1-year overall survival (Kaplan-Meir plot) of groups A, B, and $\mathrm{C}$. Abbreviation: $\mathrm{Cl}$, confidence interval.

Table 5 Comparison of the mortality rates of the elderly and the matched younger patients

\begin{tabular}{|l|l|l|l|}
\hline Mortality & $\begin{array}{l}\text { Age }>80 \\
\text { years } \\
\text { (group A) } \\
13 \text { Pts }\end{array}$ & $\begin{array}{l}\text { Matched }^{\text {a }} \\
\text { age }<80 \\
\text { years } \\
\text { (group C) } \\
\text { 13 Pts (\%) }\end{array}$ & $p$-Value \\
\hline 1-year & $1(7.7 \%)$ & $3(23.1 \%)$ & 0.215 \\
\hline 3-year & $4(30.8 \%)$ & $4(30.8 \%)$ & $>0.999$ \\
\hline
\end{tabular}

Abbreviations: Pts, patients; Yrs, years.

${ }^{\mathrm{a} G}$ roup $\mathrm{C}-$ Thirteen patients matched by gender, major and minor comorbidities, preoperative treatment (surgery/chemoradiotherapy), status of the disease (primary vs recurrence/persistence), surgical intracranial or dural extension, benign or malignant pathology, and site of skull base involvement (lateral/anterior).

retrospective studies. Since a multidisciplinary skull base team selected the patients who seem to benefit from surgical treatment, there might also be a selection bias due to patient, tumor, and physician-related factors that can never be fully accounted for.

\section{Conclusions}

The octogenarians in this study had more major comorbidities, higher malignancy rates, and were more frequently treated with neoadjuvant and adjuvant chemoradiotherapy when compared with younger patients undergoing skull base surgery. However, both the octogenarians and the younger groups of patients had a similar short- and longterm complication rate and similar 30-day and 1- and 3-year overall survival rates. Age $>80$ years by itself appears not to be a contraindication for major open skull base surgery.

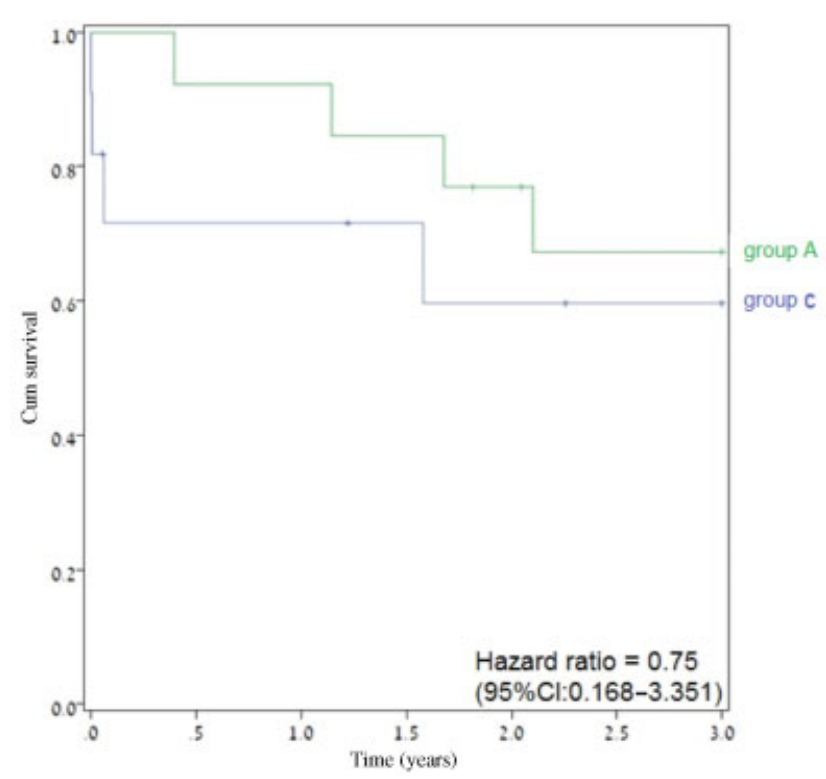

Fig. 2 The 3-year overall survival (Kaplan-Meir plot) of group A compared with group C. Abbreviation: $\mathrm{Cl}$, confidence interval.

\section{References}

1 Fentiman IS, Tirelli U, Monfardini S, et al. Cancer in the elderly: why so badly treated? Lancet 1990;335(8696):1020-1022

2 Kennedy BJ. Aging and cancer. Oncology (Williston Park) 2000;14 (12):1731-1733, discussion 1734, 1739-1740

3 Repetto L, Comandini D, Mammoliti S. Life expectancy, comorbidity and quality of life: the treatment equation in the older cancer patients. Crit Rev Oncol Hematol 2001;37(02):147-152

4 World Population Prospects. The 2015 Revision. In: United Nations, Department of Economic and Social Affairs, Population Division; 2015. https://esa.un.org/unpd/wpp/publications/files/ key_findings_wpp_2015.pdf. Accessed March 5, 2018

5 Ganly I, Patel SG, Singh B, et al. Craniofacial resection for malignant tumors involving the skull base in the elderly: an international collaborative study. Cancer 2011;117(03):563-571

6 Grammatica A, Piazza C, Paderno A, Taglietti V, Marengoni A, Nicolai P. Free flaps in head and neck reconstruction after oncologic surgery: expected outcomes in the elderly. Otolaryngol Head Neck Surg 2015;152(05):796-802

7 Hamel MB, Henderson WG, Khuri SF, Daley J. Surgical outcomes for patients aged 80 and older: morbidity and mortality from major noncardiac surgery. J Am Geriatr Soc 2005;53(03): 424-429

8 Turrentine FE, Wang H, Simpson VB, Jones RS. Surgical risk factors, morbidity, and mortality in elderly patients. J Am Coll Surg 2006; 203(06):865-877

9 Ganly I, Gross ND, Patel SG, Bilsky MH, Shah JP, Kraus DH. Outcome of craniofacial resection in patients 70 years of age and older. Head Neck 2007;29(02):89-94

10 Khafif A, Posen J, Yagil Y, et al. Quality of life in patients older than 75 years following major head and neck surgery. Head Neck 2007; 29(10):932-939

11 Yang R, Lubek JE, Dyalram D, Liu X, Ord RA. Head and neck cancer surgery in an elderly patient population: a retrospective review. Int J Oral Maxillofac Surg 2014;43(12):1413-1417

12 Patil VM, Noronha V, Joshi A, et al. Neoadjuvant chemotherapy in geriatric head and neck cancers. Head Neck 2017;39(05): 886-892 
13 Syrigos KN, Karachalios D, Karapanagiotou EM, Nutting CM, Manolopoulos L, Harrington KJ. Head and neck cancer in the elderly: an overview on the treatment modalities. Cancer Treat Rev 2009;35(03):237-245

14 VanderWalde NA, Fleming M, Weiss J, Chera BS. Treatment of older patients with head and neck cancer: a review. Oncologist 2013;18(05):568-578

15 Siddiqui F, Gwede CK. Head and neck cancer in the elderly population. Semin Radiat Oncol 2012;22(04):321-333
16 Clayman GL, Eicher SA, Sicard MW, Razmpa E, Goepfert H. Surgical outcomes in head and neck cancer patients 80 years of age and older. Head Neck 1998;20(03):216-223

17 Hentschel SJ, Nader R, Suki D, Dastgir A, Callender DL, DeMonte F. Craniofacial resections in the elderly: an outcome study. J Neurosurg 2004;101(06):935-943

18 Lalami Y, de Castro G Jr, Bernard-Marty C, Awada A. Management of head and neck cancer in elderly patients. Drugs Aging 2009;26 (07):571-583 